\title{
Relação entre a patogenicidade de Schistosoma mansoni em camundongos e a susceptibilidade do molusco vetor. I. Infecciosidade das cercárias e carga de vermes*
}

\author{
Relationship between the pathogenicity of Schistosoma mansoni in mice and the \\ susceptibility of the vector mollusc. I. Cercariae infectivity and worm burden.
}

\author{
Eliana Maria Zanotti-Magalhães**, Luiz Augusto Magalhães**, José Ferreira de Carvalho***
}

\begin{abstract}
ZANOTTI-MAGALHÃES, E.M. et al. Relação entre a patogenicidade de Schistosoma mansoni em camundongos e a susceptibilidade do molusco vetor. I. Infecciosidade das cercárias e carga de vermes. Rev. Saúde públ., 25: 359-66, 1991. Foram pesquisadas as possíveis influências que os mecanismos imunes do molusco poderiam exercer no desenvolvimento dos esporocistos e no comportamento do verme adulto no hospedeiro vertebrado. Utilizaram-se duas linhagens de $S$. mansoni (BH e SJ), selecionadas para o caráter susceptibilidade e mantidas, respectivamente, em Biomphalaria glabrata e Biomphalaria tenagophila, seus hospedeiros invertebrados naturais. Formaram-se grupos experimentais de camundongos infectados com cercárias oriundas de moluscos das duas espécies, pertencentes às gerações $P, F_{1}, F_{2}, F_{3}$ e $F_{4}$. Foram calculadas as taxas de infecção dos moluscos, número de cercárias penetrantes e o número de esquistossomos adultos nos roedores. Concluiu-se que a maior susceptibilidade de $B$. tenagophila determinou maior capacidade das cercárias em se tomarem vermes adultos. A maior susceptibilidade de $B$. glabrata originou maior capacidade de penetração das cercárias.
\end{abstract}

Descritores: Schistosoma mansoni, patogenicidade. Biomphalaria, parasitologia. Relações hospedeiroparasita.

\section{Introdução}

No Brasil, três espécies de planorbídeos têm sido descritas, naturalmente hospedando larvas de $S$. mansoni: Biomphalaria glabrata, B. tenagophila e $B$. straminea. Estas espécies de moluscos têm apresentado variado grau de susceptibilidade à infecção por S. mansoni (Ruiz ${ }^{24}$, 1957; Paraense e Correa'9 1963 ; Magalhães $^{10}$, 1969; Paraense e Correa ${ }^{21}$, 1978).

B. tenagophila do Vale do Rio Paraíba do Sul (SP, Brasil) apresenta elevado grau de resistência à infecção por $S$. mansoni de Belo Horizonte (MG, Brasil), porém é susceptível a linhagem simpátrica. B. glabrata de Belo Horizonte (MG, Brasil) é susceptível ao $S$. mansoni local, porém apresenta elevado grau de resistência à infecção por $S$. mansoni de São José dos Campos, no Vale do Rio Paraíba do Sul (SP, Brasil). Baseados nesses fatos, Paraense e Correa ${ }^{20}$ (1963) sugeriram a existência de duas linhagens do parasita: BH (Belo Horizonte) e SJ (Vale do Rio Paraíba do Sul). Segundo os autores, existi-

* Realizado com o auxílio financeiro da FINEP (Proc. 43/ 81/0417/0) e do CNPq (Proc. 40.0798/85).

** Departamento de Parasitologia do Instituto de Biologia da Universidade Estadual de Campinas.

*** Departamento de Estatística do Instituto de Matemática, Estatística e Ciência da Computação da Universidade Estadual de Campinas.

Separatas/Reprints: E.M. Zanotti-Magalhães - Cidade Universitária Barão Geraldo - 13081 - Campinas, SP, Brasil.

Publicação financiada pela FAPESP. Processo Medicina 90/4602-1. ria uma adaptação fisiológica entre o molusco e a linhagem local do parasita.

$B$. tenagophila tem sido considerada uma espécie má hospedeira do $S$. mansoni, tendo em vista os baixos índices de infecção apresentados no campo e no laboratório.

A susceptibilidade dos moluscos planorbídeos à infecção por $S$. mansoni é característica controlada geneticamente, herdável ao longo das gerações (Newton ${ }^{17}$, 1952; Richards ${ }^{22}$, 1970; Santana e col. ${ }^{25}$, 1978). Populações de $B$. glabrata e $B$. tenagophila altamente susceptiveis à infecção por $S$. mansoni das linhagens $\mathrm{BH}$ e $\mathrm{SJ}$ foram obtidas através da seleção de progênies como resultado da autofecundação dos moluscos susceptiveis (Santana e col. ${ }^{25}, 1978$ ).

Diferenças de comportamento das linhagens $\mathrm{BH}$ e SJ foram observadas também no hospedeiro definitivo. Magalhães e Carvalho ${ }^{12,13,14,15}$ (1969, 1973, 1976) verificaram que número bem menor de parasitas da linhagem BH provoca níveis equivalentes de nocividade aos provocados por maior número de vermes da linhagem SJ.

Nas áreas endêmicas, habitadas por B. glabrata, encontram-se indivíduos com esquistossomose na forma hepatosplênica descompensada, enquanto nas áreas onde o homem se infecta através da $B$. tenagophila, a maioria dos portadores do parasita são assintomáticos (Dias e col. ${ }^{3}, 1988$ ).

O maior grau de nocividade apresentado pelo $S$. mansoni da linhagem BH pode ser um reflexo da facilidade com que as larvas do trematódeo se desenvolvem em $B$. glabrata. Da mesma forma, o me- 
nor grau de nocividade do $S$. mansoni da linhagem SJ poderá ser decorrente da maior resistência oferecida pelo molusco vetor ao desenvolvimento da larva parasita. Saoud ${ }^{26}$ (1966) sugeriu que um dos fatores que determinaria a patogenicidade dos esquistossomos seria o grau de infectividade dos hospedeiros intermediários.

Mecanismos celulares e humorais estão envolvidos na resistência e na susceptibilidade dos moluscos diante dos esporocistos de trematódeos (Bayne e col. ', 1980; Granath e Yoshino ${ }^{6}, 1984$ ).

Guaraldo e col. ${ }^{7}$ (1981), estudando as reaçōes amebocitárias em $B$. glabrata de Belo Horizonte e em $B$. tenagophila de São José dos Campos expostas ao $S$. mansoni das linhagens $\mathrm{BH}$ e SJ, respectivamente, verificaram grande número de esporocistos degenerados na última espécie, enquanto na primeira espécie predominavam esporocistos viáveis. Em moluscos selecionados geneticamente para o caráter susceptibilidade, os autores verificaram não haver reação amebocitária em torno dos esporocistos, em ambas as espécies de moluscos.

Que influências exerceriam os mecanismos imunológicos do molusco sobre o ciclo do $S$. mansoni e seu comportamento no hospedeiro definitivo? Que implicações resultariam para a patogênese do $S$. mansoni no hospedeiro definitivo, o fato dos esporocistos terem se desenvolvido num meio favorável, sem sofrer as conseqüências das reações amebocitárias? Ou ao contrário, terem se desenvolvido em meio hostil devido a intensa reação amebocitária?

Com a finalidade de responder a essas perguntas, estudamos a patogenicidade do $S$. mansoni, oriundo de $B$. glabrata e $B$. tenagophila selecionadas geneticamente para o caráter susceptibilidade. Nesta primeira fase, avaliamos o grau de infecciosidade das cercárias e a carga parasitária em camundongos submetidos à infecção com larvas provenientes de moluscos com diferentes graus de susceptibilidade.

\section{Material e Método}

\section{Animais Utilizados}

a. Moluscos vetores. Como se desejavam moluscos com diferentes graus de susceptibilidade, foram obtidas, por autofecundação dos moluscos susceptíveis, progênies de $B$. glabrata e $B$. tenagophila expostas, respectivamente, às linhagens $\mathrm{BH}$ e SJ de $S$. mansoni.

Os moluscos da geração parental eram descendentes de $B$. glabrata originária de Belo Horizonte e de $B$. tenagophila oriunda de São José dos Campos. Foram obtidas cinco gerações de moluscos designadas: $B$. glabrata $P$ (geração parental), $F_{1}, F_{2}, F_{3}$ e $F_{4}$ e $B$. tenagophila $P$ (geração parental), $F_{1}, F_{2}, F_{3}^{3}$ e $F_{4}$. Os miracídios utilizados na infecção dos moluscos da geração parental foram designados " $S$. mansoni da geração parental" (BHP e SJP). Os moluscos foram infectados logo após ter-se observado as primeiras desovas, o que ocorreu quando os moluscos mediam em torno de 7 a $10 \mathrm{~mm}$ de diâmetro. A infecção foi realizada pela exposição, sob luz e temperatura de $28^{\circ} \mathrm{C}$, a 10 miracídios durante 2 horas.

Decorridos 30 dias da data da infecção, os moluscos foram examinados para verificação da eliminação de cercárias. Planorbídeos submetidos à infecção foram observados, semanalmente, durante seis meses, para a determinação de sua susceptibilidade, através do cálculo da taxa de infecção. Os moluscos foram mantidos em frascos individuais, com água declorada sendo alimentados com alface " $a d$ libitum". Através da infecção de camundongos, com cercárias eliminadas pelos moluscos, foram obtidas gerações correspondentes de $S$. mansoni, para cada linhagem: geração parental (BHP e SJP); $F_{\text {(BHF }}$ e $\left.\mathrm{SJF}_{1}\right) ; \mathrm{F}_{2}\left(\mathrm{BHF}_{2}\right.$ e $\left.\mathrm{SJF}_{2}\right) ; \mathrm{F}_{3}\left(\mathrm{BHF}_{3}\right.$ e $\left.\mathrm{SJF}_{3}\right)$ e $\mathrm{F}_{4}^{\prime}$ $\left(\mathrm{BHF}_{4}\right.$ e $\left.\mathrm{SJF}_{4}\right)$.

b. Hospedeiros definitivos. Os animais utilizados como hospedeiros definitivos do $S$. mansoni foram camundongos Swiss fêmeos, oriundos do Biotério Central da Unicamp.

Por ocasião do início do experimento, os animais tinham 30 dias de idade.

As cercárias utilizadas para infecção foram provenientes das respectivas gerações de moluscos, de maneira que, ao final do experimento, dois grupos de camundongos haviam sido constituídos: animais infectados com a linhagem $\mathrm{BH}$ e animais infectados com a linhagem SJ.

O grupo de camundongos infectados com a linhagem $\mathrm{BH}$ foi composto de cinco subgrupos de roedores:

1) 20 camundongos infectados com cercárias de B. glabrata da geração parental (BHP).

2) 19 camundongos infectados com cercárias de B. glabrata da geração $\mathrm{F}_{1}\left(\mathrm{BHF}_{1}\right)$.

3) 20 camundongos infectados com cercárias de B. glabrata da geração $\mathrm{F}_{2}\left(\mathrm{BHF}_{2}\right)$.

4) 27 camundongos infectados com cercárias de $B$. glabrata da geração $\mathrm{F}_{3}\left(\mathrm{BHF}_{3}\right)$.

5) 25 camundongos infectados com cercárias de $B$. glabrata da geração $\mathrm{F}_{4}\left(\mathrm{BHF}_{4}\right)$.

$\mathrm{O}$ grupo de camundongos infectados com a linhagem SJ foi constituido de cinco subgrupos:

1) 14 camundongos infectados com cercárias originadas em B. tenagophila da geração parental (SJP).

2) 18 camundongos infectados com cercárias originadas em $B$. tenagophila da geração $\mathrm{F}_{1}\left(\mathrm{SJF}_{1}\right)$.

3) 19 camundongos infectados com cercárias originadas em B. tenagophila da geração $\mathrm{F}_{2}\left(\mathrm{SJF}_{2}\right)$. 
4) 18 camundongos infectados com cercárias originadas em $B$. tenagophila da geração $\mathrm{F}_{3}\left(\mathrm{SJF}_{3}\right)$.

5) 10 camundongos infectados com cercárias originadas em $B$. tenagophila da geração $\mathrm{F}_{4}\left(\mathrm{SJF}_{4}\right)$.

Os subgrupos de camundongos foram constituídos à medida que as cercárias foram sendo eliminadas pelos caramujos.

\section{Infecção dos Camundongos}

Os camundongos foram infectados imergindo suas caudas em tubo de ensaio contendo 100 cercárias. Ao fim de 2 horas de exposição, foi determinado o número de cercárias penetrantes, segundo técnica de Magalhães" (1969).

$\mathrm{Na}$ oitava semana de infecção, os animais sobreviventes foram sacrificados por deslocamento cervical e os vermes coletados através da perfusão do sistema porta-hepático, segundo técnica de Yolles e col. ${ }^{28}$ (1947).

\section{Métodos de Análise Estatística}

A análise dos resultados foi feita para cada variável-resposta separadamente. Procedeu-se, basicamente, ao ajuste de uma reta, em função da taxa de infecção dos moluscos, para cada uma das duas linhagens. Isto foi feito, para cada resposta de uma só vez, usando-se o procedimento GLM do SAS'. Extensas análises de resíduos foram realizadas para validarem-se os modelos.

\section{Resultados}

Na tabela 1 estão apresentadas as taxas de infecção verificadas em $B$. glabrata e $B$. tenagophila, das gerações parental $\left(\mathrm{P}_{0}\right), \mathrm{F}_{1}, \mathrm{~F}_{2}, \mathrm{~F}_{3}$ e $\mathrm{F}_{4}$ submetidas à infecção por $S$. mansoni respectivamente, das linhagens $\mathrm{BH}$ e SJ. Taxas de infecção maiores foram observadas logo na geração $F_{1}$ e se mostraram mai-
Tabela 1 - Taxa de infecção das gerações de $B$. glabrata e $B$. tenagophila submetidas à infecção pelas correspondentes gerações de $S$. mansoni, respectivamente das linhagens BH e SJ.

\begin{tabular}{lcccc}
\hline Espécie & $\begin{array}{l}\text { Geração do } \\
\text { molusco e do } \\
\text { S. mansoni }\end{array}$ & $\begin{array}{l}\mathrm{N}^{2} \text { de moluscos } \\
\text { examinados }\end{array}$ & $\begin{array}{l}\text { No de moluscos } \\
\text { que eliminaran } \\
\text { cercárias }\end{array}$ & $\begin{array}{l}\text { Taxa de } \\
\text { infecção (\%) }\end{array}$ \\
\hline B. glabrata & $\mathrm{P}$ & 50 & 22 & 44 \\
& $\mathrm{~F}_{1}$ & 29 & 20 & 69 \\
& $\mathrm{~F}_{2}$ & 66 & 48 & 73 \\
& $\mathrm{~F}_{3}$ & 19 & 14 & 74 \\
& $\mathrm{~F}_{4}$ & 20 & 12 & 60 \\
\hline B. tenagophila & $\mathrm{P}$ & 59 & 9 & 15 \\
& $\mathrm{~F}_{1}$ & 72 & 35 & 49 \\
& $\mathrm{~F}_{2}$ & 47 & 28 & 60 \\
& $\mathrm{~F}_{3}$ & 52 & 35 & 67 \\
& $\mathrm{~F}_{4}$ & 27 & 7 & 26 \\
\hline
\end{tabular}

ores ainda nas duas gerações subseqüentes de moluscos. $\mathrm{Na}$ geração $\mathrm{F}_{4}$, tanto em $B$. glabrata quanto em $B$. tenagophila, observou-se uma queda na taxa de infecção, embora não tenha alcançado o valor obtido em $P$.

O número de cercárias penetrantes e o número de esquistossomos, verificados nos camundongos expostos às larvas originadas nos moluscos selecionados, estão apresentados na Tabela 2 . Os resultados apresentados na Tabela 3 , evidenciam as diferenças de efeitos da taxa de infecção entre as linhagens, através das análises de variância. Os valores esperados de cada resposta, para cada linhagem e taxa de infecção, estão nas Figuras 1, 2, 3 e 4 que mostram de modo mais direto o efeito quantitativo.

$\mathrm{Na}$ linhagem $\mathrm{BH}$, o número de cercárias penetrantes foi maior com a maior taxa de infecção dos moluscos. Na linhagem $\mathrm{SJ}$, o número de cercárias penetrantes foi maior do que na linhagem $\mathrm{BH}$, pou-

Tabela 2 - Número médio de cercárias penetrantes e de esquistossomos verificados nos camundongos infectados com as linhagens BH e SJ de S. mansoni.

\begin{tabular}{|c|c|c|c|c|c|}
\hline \multirow{3}{*}{$\begin{array}{l}\text { Linhagem } \\
\mathrm{BH}\end{array}$} & \multirow{3}{*}{$\begin{array}{c}\text { Geraçāo } \\
P \\
F_{1} \\
F_{2} \\
F_{3} \\
F_{4}\end{array}$} & \multirow{2}{*}{$\begin{array}{l}\mathrm{N}^{\circ} \text { de cercárias } \\
\text { penetrantes }\end{array}$} & \multicolumn{3}{|c|}{$\mathrm{N}^{2}$ de esquistossomos } \\
\hline & & & Machos & Fêmeos & \multirow{2}{*}{$\begin{array}{l}\text { Total } \\
56,76 \pm 19,01 \\
44,42 \pm 16,37 \\
54,90 \pm 15,93 \\
46,44 \pm 16,18 \\
66,60 \pm 15,48\end{array}$} \\
\hline & & 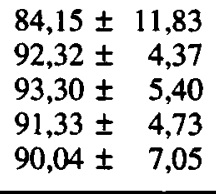 & $\begin{array}{l}20,00 \pm 8,87 \\
21,92 \pm 8,67 \\
29,00 \pm 9,81 \\
24,61 \pm 10,26 \\
38,00 \pm 13,16\end{array}$ & $\begin{array}{r}36,76 \pm 12,94 \\
22,50 \pm 8,37 \\
25,90 \pm 9,36 \\
21,83 \pm 9,73 \\
28,60 \pm 10,94\end{array}$ & \\
\hline SJ & $\begin{array}{l}\mathrm{P} \\
\mathrm{F}_{1} \\
\mathrm{~F}_{2} \\
\mathrm{~F}_{3} \\
\mathrm{~F}_{4}\end{array}$ & 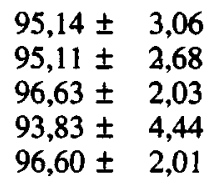 & $\begin{array}{l}24,92 \pm 9,77 \\
45,07 \pm 9,35 \\
51,91 \pm 14,66 \\
44,44 \pm 11,25 \\
44,75 \pm 13,09\end{array}$ & $\begin{array}{r}14,67 \pm 6,77 \\
24,36 \pm 7,48 \\
15,09 \pm 5,34 \\
25,00 \pm 7,83 \\
9,25 \pm 3,73\end{array}$ & $\begin{array}{l}39,58 \pm 7,28 \\
69,43 \pm 10,42 \\
67,00 \pm 14,93 \\
69,44 \pm 13,50 \\
54,00 \pm 14,86\end{array}$ \\
\hline
\end{tabular}


Tabela 3 - Análise de variância (soma dos quadrados do tipo III) por respostas.

\begin{tabular}{|c|c|c|c|c|c|c|c|c|}
\hline \multirow{2}{*}{$\begin{array}{l}\text { Resposta } \\
\text { Fonte de } \\
\text { Variação }\end{array}$} & \multicolumn{2}{|c|}{$\begin{array}{c}\text { № de cercárias } \\
\text { penetrantes }\end{array}$} & \multicolumn{2}{|c|}{$\begin{array}{c}\text { № de vermes } \\
\text { Machos }\end{array}$} & \multicolumn{2}{|c|}{$\begin{array}{c}\text { № de vermes } \\
\text { Fêmeos }\end{array}$} & \multicolumn{2}{|c|}{$\begin{array}{c}\text { № de vermes } \\
\text { Totais }\end{array}$} \\
\hline & Valor & Nível & Valor & Nível & Valor & Nível & Valor & Nível \\
\hline $\begin{array}{l}\text { Linhagem } \\
\text { soma dos quadrados } \\
\text { graus de liberdade }\end{array}$ & $\begin{array}{c}1276,8 \\
1\end{array}$ & 0,0001 & $\begin{array}{c}120,5 \\
1\end{array}$ & 0,3615 & $\begin{array}{c}4195,8 \\
1\end{array}$ & 0,0001 & $\begin{array}{c}1046,0 \\
1\end{array}$ & 0,0328 \\
\hline $\begin{array}{l}\text { Taxa (linhagem) } \\
\text { soma dos quadrados } \\
\text { grau de liberdade }\end{array}$ & $\begin{array}{c}939,0 \\
2\end{array}$ & 0,0001 & $\begin{array}{c}3243,1 \\
2\end{array}$ & 0,0001 & $\begin{array}{c}2929,3 \\
2\end{array}$ & 0,0001 & $\begin{array}{c}11660,6 \\
8\end{array}$ & 0,0001 \\
\hline $\begin{array}{l}\text { Resíduo } \\
\text { soma dos quadrados } \\
\text { grau de liberdade }\end{array}$ & $\begin{array}{c}6217,5 \\
186\end{array}$ & & $\begin{array}{c}16798,3 \\
117\end{array}$ & & $\begin{array}{c}10320,3 \\
117\end{array}$ & & $\begin{array}{c}24846,3 \\
111\end{array}$ & \\
\hline
\end{tabular}

co variando com a maior susceptibilidade de $B$. tenagophila (Tabela 3, Fig. 1).

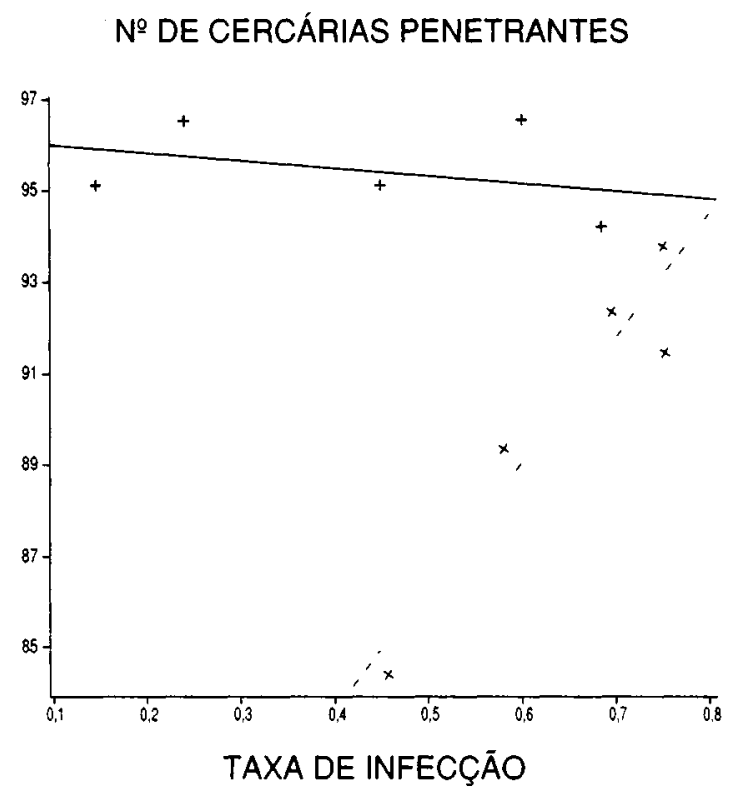

$\mathrm{x}-\mathrm{BH}$

$+-\mathrm{SJ}$

Figura 1. Número de cercárias penetrantes das linhagens $\mathrm{BH}$ e SJ em função das taxas de infecção apresentadas por B. glabrata e B. tenagophila selecionadas.

Verificou-se maior número de esquistossomos machos quando os animais foram infectados pela linhagem SJ. Observou-se maior número de vermes machos quando a taxa de infecção dos moluscos de ambas espécies era mais elevada (Tabela 3, Fig. 2).

\section{NN DE VERMES MACHO}

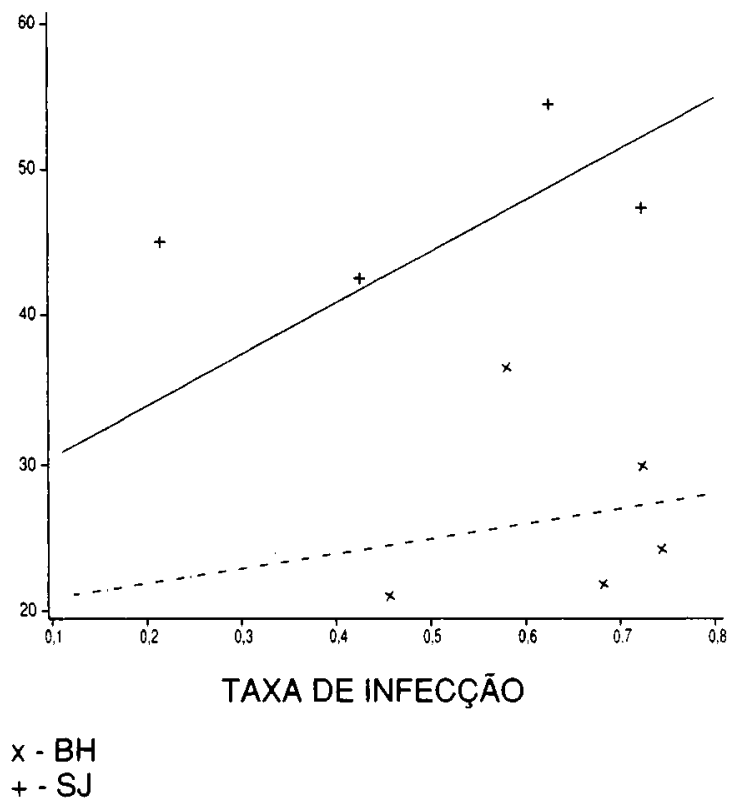

Figura 2. Número de esquistossomos machos das linhagens $\mathrm{BH}$ e SJ em função das taxas de infecção apresentadas por $B$. glabrata e $B$. tenagophila selecionadas.

Taxas de infecção maiores para $B$. tenagophila e $B$. glabrata determinaram comportamento diferente no número de esquistossomos fêmeos: na linhagem SJ verificou-se número maior de esquistossomos fêmeos e, na linhagem BH, número menor (Tabela 3, Fig. 3). 


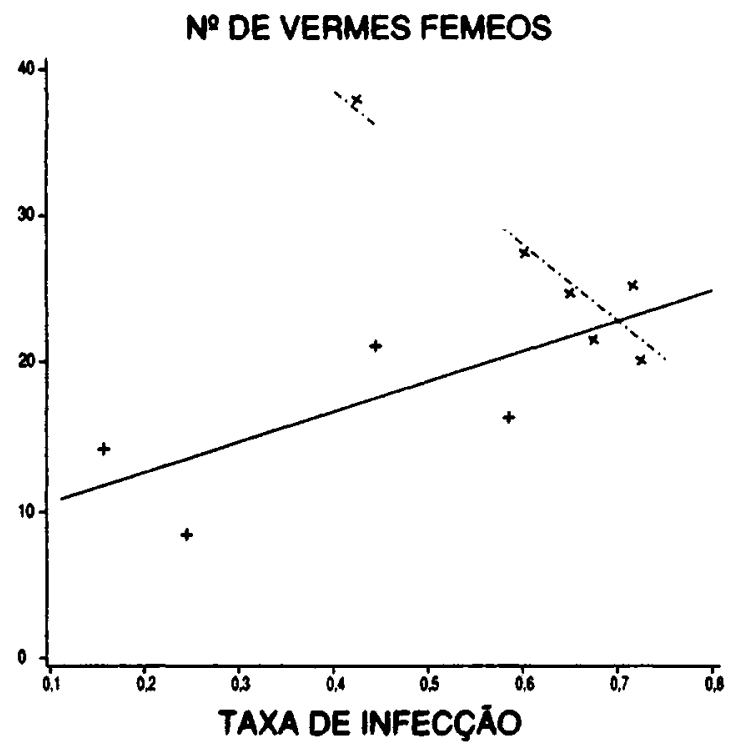

$X-B H$

+- SN

Figura 3. Número de esquistossomos fêmeos das linhagens BH e SJ em função das taxas de infecção apresentadas por $B$. glabrata e B. tenagophila selecionadas.

O número de esquistossomos totais foi acentuadamente maior quando os camundongos foram infectados por cercárias da linhagem SJ, provenientes de moluscos que apresentaram maior grau de susceptibilidade (Tabela 3, Fig. 4).

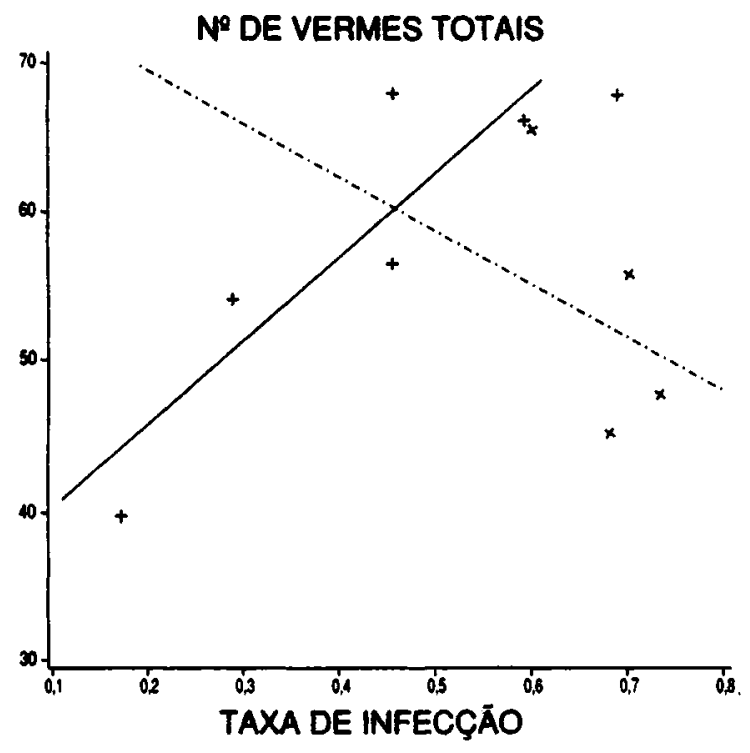

$x-B H$

$+\cdot \mathbf{S J}$

Fiqura 4. Número de esquistossomos totais das linhagens BH e SJ em funçäo das taxas de infecção apresentadas por B. glabrata e B. tenagophila.
Nos camundongos infectados pela linhagem $\mathrm{BH}$ observou-se maior número de esquistossomos totais quando as cercárias eram provenientes de moluscos mais susceptíveis (Tabela 3, Fig. 4).

\section{Discussão e Conclusões}

Baseados nos resultados de Newton ${ }^{18}$ (1953); Richards e Merritt ${ }^{23}$ (1972) e Santana e col. ${ }^{25}$ (1978), desenvolveu-se um esquema de seleção, por autofecundação de $B$. glabrata e $B$. tenagophila susceptíveis à infecção por $S$. mansoni das linhagens $\mathrm{BH}$ e SJ, respectivamente. Como mostram os resultados apresentados na Tabela 1, obtiveram-se progênies de moluscos com taxas crescentes de infectividade.

Diferentes taxas de infecção têm sido observadas por diferentes pesquisadores, quando submetem à infecção diferentes populações de $B$. glabrata e de $B$. tenagophila (Files e Cram ${ }^{4}, 1949$; Ruiz ${ }^{24}, 1957$; Paraense e Correa ${ }^{1920,21}, 1963,1978$; Magalhães ${ }^{10}$, 1969). Há porém, concordância em assinalar que $B$. tenagophila apresenta taxas de infecção, tanto no campo como em laboratório, inferiores a $B$. glabrata (Paraense e Correa ${ }^{19,20.21}, 1963,1978$ ).

A seleção genética promovida por Newton ${ }^{18}$ (1953), Richards e Merritt ${ }^{23}$ (1972), Santana e col. ${ }^{25}$ (1978) e agora por nós realizada, seleciona moluscos ajustados fisiologicamente ao parasitismo por $S$. mansoni.

No decorrer do experimento foi isolada, paralelamente à obtenção de progênies de moluscos, uma população de $S$. mansoni resultante de passagens sucessivas nos moluscos selecionados. Esse fato poderia explicar as taxas de infecção obtidas, mais baixas em relação às taxas verificadas por Santana $e$ col..$^{25}$ (1978). Os moluscos eram adaptados a uma determinada população de $S$. mansoni (geração parental do verme). Como selecionaram-se, no decorrer do experimento, populações de $S$. mansoni, a constituição genética da geração inicial do trematódeo deverá ter sofrido modificações decorrentes de pressões seletivas. Segundo Fredsen ${ }^{5}$ (1979), pouco se tem discutido sobre a pressão de seleção exercida pela utilização constante de uma determinada espécie de hospedeiro vertebrado e invertebrado ou, mesmo, quanto às pressões provenientes das condições de laboratório, que atuariam no comportamento do $S$. mansoni. Esta pressão seletiva parece ter sido demonstrada por Conceição e Coura $^{2}$ (1983), que observaram comportamento diferente de $B$. glabrata, quando submetida a amostras de $S$. mansoni isoladas de pacientes com diferentes formas clínicas de esquistossomose. Além das pressões seletivas, essas observações parecem confirmar o papel da constituição genética e da biologia do parasita e do vetor no desenvolvimento do quadro patológico da esquistossomose. 
Tendo em vista atingir os objetivos do trabalho, obtiveram-se populações de $B$. glabrata e $B$. tenagophila com crescentes taxas de susceptibilidade à infecção por $S$. mansoni e que certamente, em nível tissular, apresentaram uma decrescente reação amebocitária ao desenvolvimento dos esporocistos, como foi sobejamente demonstrado por Newton ${ }^{17}$ (1952); Sullivan e Richards ${ }^{27}$ (1981) e Guaraldo e col.' (1981), ao examinarem cortes histológicos de moluscos resistentes e susceptíveis à infecção por $S$. mansoni. A diminiuição da taxa de susceptibilidade observada nas gerações $\mathrm{F}_{4}$ poderá ter sido consequiência de fatores ambientes, em virtude da menor variabilidade genética das populações endogâmicas selecionadas.

Populações com alto grau de endogamia apresentam menor variabilidade enzimática. Essas populações são, conseqüentemente, muito mais sensíveis às variações de ambiente, que podem determinar mudanças de comportamento facilmente perceptíveis ao observador (perda de peso, menor crescimento, e outros) ou outras perceptiveis somente no decurso do experimento, como a menor susceptibilidade ora observada.

Os mecanismos que participam na penetração das cercárias constituem assunto de alta complexidade: estas larvas em curto espaço de tempo mudam de ambiente, emergindo do molusco em que se desenvolvem, para o meio aquático e, em seguida, para os tecidos do hospedeiro vertebrado. $O$ ambiente fornecido pelo organismo do hospedeiro vertebrado é dinamicamente ativo, apresentando reações à presença das larvas, de modo a estabelecer-se o início do relacionamento que irá perdurar durante todo o parasitismo. Segundo Miller e Wilson ${ }^{16}(1978)$ a pele do camundongo constitui uma barreira intransponível para 60 a $70 \%$ das cercárias de S. mansoni.

Magalhães e Carvalho ${ }^{12}$ (1969) e, posteriormente, Lemos Neto e col. ${ }^{9}$ (1978) verificaram que cercárias da linhagem $\mathrm{BH}$ apresentavam maior capacidade de penetração que cercárias da linhagem SJ.

Constrastando com esses resultados, no presente trabalho verificou-se que cercárias da linhagem $\mathrm{BH}$ apresentaram menor capacidade de penetração no tegumento de camundongos, do que cercárias da linhagem SJ (Tabela 3, Fig. 1).

Observando-se a Figura 1, podemos afirmar, no caso da linhagem $\mathrm{BH}$, que a maior susceptibilidade da $B$. glabrata determinou maior capacidade de penetração das cercárias. Na linhagem SJ, o número de cercárias penetrantes pouco variou em decorrência da maior susceptibilidade do molusco.

$\mathrm{Na}$ capacidade de penetração das cercárias, o trinômio constituído pelo molusco, no qual as cercárias se desenvolveram, pelas próprias cercárias e pelo hospedeiro definitivo tem de ser considerado.
Como os hospedeiros definitivos utilizados no experimento foram de uma única espécie, linhagem e idade, devem ser apreciadas as modificações ocorridas nos moluscos, em virtude da seleção genética e possíveis alterações no comportamento das cercárias, mesmo admitindo ser possível a existência de variações intra-específicas no hospedeiro vertebrado, influenciando na capacidade de penetração da larva.

Newton ${ }^{17}$ (1952); Kassim e Richards ${ }^{8}$ (1979); Guaraldo e col. ${ }^{7}$ (1981) e Sullivan e Richards ${ }^{27}$ (1981) verificaram que reações teciduais, envolvendo células amebocitárias, impedem ou dificultam o desenvolvimento de esporocistos em moluscos pouco susceptíveis à infecção esquistossomótica. Quando moluscos são susceptíveis às infecções esquistossomóticas, as reações amebocitárias são discretas e por vezes imperceptíveis e os esporocistos se desenvolvem com vigor. Aventou-se a hipótese de que as cercárias originadas em moluscos mais susceptíveis teriam maior vigor e capacidade de penetração no hospedeiro vertebrado. Para a linhagem $\mathrm{BH}$, os atuais resultados confirmaram a hipótese. Nas infecções por helmintos a carga parasitária está relacionada com a gravidade da doença no hospedeiro. Em se tratando de $S$. mansoni o número de vermes presentes no hospedeiro é de importância relativa, desde que a patogênese das infecções por $S$. mansoni está mais diretamente relacionada com a presença de reações granulomatosas em torno do ovo do parasita. Saoud ${ }^{26}$ (1966), estudando o desenvolvimento de várias linhagens geográficas de $S$. mansoni, verificou que a linhagem egípcia era menos patogênica apesar do grande número de vermes observado nos camundongos.

Magalhães e Carvalho ${ }^{12,14,15}(1969,1973,1976)$, estudando o desenvolvimento das linhagens $\mathrm{BH}$ e $\mathrm{SJ}$ do $S$. mansoni em camundongos, verificaram que, apesar do número de vermes não diferir entre uma linhagem e outra, a linhagem BH é mais patogênica por dar origem a maior número de granulomas hepáticos.

Considerando o número de vermes totais relacionados com a susceptibilidade dos moluscos que deram origem às cercárias, foram obtidos resultados contraditórios para a linhagem BH e SJ. Na linhagem SJ, verificou-se maior número de esquistossomos nos grupos de roedores infectados com cercárias de moluscos mais susceptíveis. $\mathrm{Na}$ linhagem $\mathrm{BH}$, não se evidenciou uma tendência ao aumento do número de vermes. É de crer que este fato seja decorrente do maior aumento de susceptibilidade obtida pela seleção de $B$. tenagophila. $\mathrm{Na}$ realidade, no caso da população de $B$. glabrata utilizaram-se moluscos que apresentavam, desde o início do experimento, elevado grau de susceptibilidade à infecção, quando comparada com B. tenagophila.

As linhagens $\mathrm{BH}$ e $\mathrm{SJ}$ de $S$. mansoni são mantidas 
em nosso laboratório em moluscos simpátricos, $B$. glabrata e $B$. tenagophila, respectivamente, originados de populações oriundas de Belo Horizonte e do Vale do Rio Paraíba do Sul. As linhagens foram isoladas de moluscos colhidos no campo e que apresentaram eliminação de cercárias. Periodicamente, moluscos e parasitas colhidos no campo têm sido introduzidos no laboratório, realimentando-se, dessa maneira, o material genético das espécies. Convém assinalar que a taxa de infecção apresentada por $B$. tenagophila do Vale do Rio Paraíba é baixa, o que dificulta muitas vezes a manutenção do ciclo no laboratório, enquanto $B$. glabrata se mostra bem mais susceptivel.

Como constatação final verificou-se que a maior susceptibilidade de $B$. tenagophila influiu na maior capacidade das cercárias em se tornarem vermes adultos, enquanto cercárias oriundas de $B$. glabrata selecionada apresentaram apenas maior capacidade de penetração à medida que o molusco tornou-se mais susceptível. Essa maior capacidade de penetração das cercárias BH oriundas de moluscos mais susceptíveis determinou maior desenvolvimento de vermes machos, porém. uma acentuada queda no número de vermes fêmeos, proporcionando uma queda no número total de vermes à medida que aumentou a susceptibilidade dos moluscos.

ZANOTTI-MAGALHÃES, E.M. et al. [Relationship between the pathogenicity of Schistosoma mansoni in mice and the susceptibility of the vector mollusc. I. Cercariae infectivity and worm burden]. Rev. Saúde públ., S. Paulo, 25: 359-66, 1991. The possible influence of the immune mechanisms of the molluscs on the developmente of the sporocysts and the resultant behavior of the adult worm in the vertebrate host were studied. Two strains of Schistosoma mansoni (BH and SJ) were used. These were genetically selected for their susceptibility and maintained, respectively, in Biomphalaria glabrata and Biomphalaria tenegophila, the natural invertebrate hosts. Experimental groups of mice infected with cercariae proceeding from the two species of molluscs, belonging to generations $P$, $F_{1}, F_{2}, F_{3}$ and $F_{4}$, were formed. The infection rates of the snails, the number of the penetrant cercariae and the worm burden in mice were evaluated. It was concluded that the higher susceptibility of Biomphalaria tenagophila results in a greater ability on the part of the cercarial to develop into adult worms. The higher susceptibility of $B$. glabrata results in greater power of penetration into mice tegument on the part of the cercariae.

Keyu'ords: Schistosoma mansoni, patogenicity. Biomphlaria, parasitology. Host-parasite relations.

\section{Referências Bibliográficas}

1. BAYNE, C.J.; BUCKLEY, P.M.; DEWAN, P.C. Schistosoma mansoni: cytotoxicity of hemocytes from susceptible hosts for sporocysts in plasma from resistant Biomphalaria glabrata. Exp. Parasit, 50: 409-16, 1980.
2. CONCEIÇĀO, M.J. \& COURA, J.R. Comportamento experimental em Biomphalaria glabrata de amostras de $S$ mansoni isoladas de pacientes com diferentes formas chinicas de esquistosomose. [Apresentado ao XIX Congresso da Sociedade Brasileira de Medicina Tropical, Rio de Janeiro, 1983]

3. DIAS, L.C.S.: GLASSER, C.M.; ETZEL, A.: KAWAZOE, U.: HOSHINO-SHIMIZU, S.; KANAMURA, H.Y.; CORDEIRO, J.A.: MARÇAL JR., O.; CARVALHO, J.F.: GONÇALVES JR., F.; PATUCCI, R. The epidemiology and control of schistosomiasis mansoni where Biomphalaria tenagophila is the snail host. Rev. Saúde públ., S. Paulo, 22: 462-3, 1988.

4. FILES, V.S. \& CRAM. E.B. A study on the comparative susceptibility of snail vectors to strains of Schistosoma mansoni. J. Parasit., 35: 555-60, 1949.

5. FREDSEN, F. Discussion of the relationship between Schistosoma and their intermediate hosts assessment of the degree of host-parasite compatibility and evaluation of schistosome taxonomy. Z. Parasitenkd., 58: 275-96, 1979.

6. GRANATH JR, W.O.; YOSHINO, T.P. Schistosoma mansoni: passive transfer of resistance by serum in the vector snail Biomphalaria glahrata. Exp. Parasit, 58: 188-93, 1984.

7. GUARALDO, A.M.A.; MAGALHÃES, L.A.; RANGEL, H.A.; PAREJA, G. Evolução dos esporocistos de Schistosoma mansoni Sambon, 1907, em Biomphalaria Glabrata (Say, 1818) e Btomphalaria tenagophila (D’Orbigny, 1835). Rev'. Saúde públ., S. Paulo, 15: 436. 48. 1981.

8. KASSIN. O.O. \& RICHARDS, C.S. Host reactions in Biomphaluria glabrata to Schistosoma mansoni miracidia involving variation in parasite strains numbers and sequence of exposures. Im. J. Parasit., 9: 565-70. 1979.

9. LEMOS NETO, R.C.: MAGALHÃES, L.A. PIEDRABUENA, A.E. Alguns aspectos referentes ao estudo de linhagens de Schistosoma mansoni Sambon, 1907 provenientes dos Estados de Minas Gerais e de São Paulo, Brasil. Rev. Saúde públ., S. Paulo, 12: 277-90, 1978.

10. MAGALHÃES, L.A. Estudo dos dados obtidos de uma população de Biomphalaria glabrata de Belo Horizonte infectada por Schistosoma munsoni da mesma cidade e de uma população de Biomphataria tenagophila de Campinas infectada por $S$. mansoni de São José dos Campos. Rev. Soc. hras. Med trop., 3: 195-6, 1969.

11. MAGALHĀES, L.A. Técnica para a avaliação da viabilidade de penetração de cercárias de Schistosoma mansoni em Mus musculus. Hospital, Rio de Janeiro, 75: 137-40, 1969.

12. MAGALHÃES, L.A. \& CARVALHO, J.F. de. Verificação do número de machos e fêmeas de Schistosoma mansoni capturados em camundongos infectados com duas cepas do helminto. Rev. Soc. bras. Med. trop., 3: 253-4, 1969.

13. MAGALHÃES, L.A. \& CARVALHO, J.F. de. Determinação do número de cercárias provenientes de cepas diferentes de Schistosoma mansoni que conseguem penetrar sob condições de laboratório em Mus musculus. Rev. Soc. bras. Med. rop., 3: 249-51, 1969.

14. MAGALHÃES. L.A. \& CARVALHO, J,F. de. Desenvolvimento do Schistosoma mansoni das linhagens de Belo Horizonte (MG) e de São José dos Campos (SP) em Mus musculus. Rev. Saúde públ., S. Paulo, 7: 285-7, 1973.

15. MAGALHĀES, L.A. \& CARVALHO, J.F. de. Sobre o comportamento de duas linhagens de Schistosoma mansoni Sambon, 1907. Proposiçāo para método de estudo quantitativo. Rev. Soc. bras. Med. rrop., 10: 169-94, 1976.

16. MILLER, P. \& WILSON, R.A. Migration of the schistosomula of Schistosoma mansoni from skin to lungs. Parasitology, 77: 281-302, 1978.

17. NEWTON, W.L. The comparative tissue reaction of two strains of Australorbis glabratus to infection with Schistosoma mansoni. J. Parasit., 38: 362-6, 1952. 
18. NEWTON, W.L. The inheritance of susceptibility to infection with Schistosoma mansoni in Australorbis glabratus. Exp. Parasit., 2: 242-57, 1953.

19. PARAENSE, W.L. \& CORREA, L.R. Variation in susceptibility of populations of Australorbis glabratus to a strain of a Schistosoma mansoni. Rev. Inst. Med. rop. S. Paulo, 5: 15-22, 1963.

20. PARAENSE, W.L. \& CORREA, L.R. Susceptibility of Australorbis tenagophilus to infection with Schistosoma mansoni. Rev. Inst. Med. rop., S. Paulo, 5: 23-9, 1963.

21. PARAENSE, W.L. \& CORREA, L.R. Differential susceptibility of Biomphalaria tenagophila populations to infection with a strain of Schistosoma mansoni. J. Parasit., 64: 822-6, 1978.

22. RICHARDS, C.S. Genetic of a molluscan vector of schistosomiasis. Nature, 227: 806-10, 1970.

23. RICHARDS, C.S. \& MERRITT JR., J.W. Genetic factors in the susceptibility of juvenile Biomphalaria glabrata to Schistosoma mansoni infection. Amer. J. trop. Med. Hyg., 21: 425-34, 1972.

24. RUIZ, J.M. Esquistosomose experimental. 5. Dados sobre infestaçāo experimental de Biomphalaria tenagophila
(Orbigny) e Australorbis glabratus (Say). Rev. bras. Biol., 17: 179-85, 1957.

25. SANTANA, J.V. de.; MAGALHÃES, L.A.; RANGEL, H. de A. Seleçẫo de linhagem de Biomphalaria glabrata e $B$. tenagophila visando maior susceptibilidade ao Schistosoma mansoni. Rev. Saúde públ., S. Paulo, 12: 67. 77, 1978.

26. SAOUD, M.F.A. The infectivity and pathogenicity of geographical strains of Schistosoma mansoni. Trans. roy. Soc. trop. Med. Hyg., 60: 585-600, 1966.

27. SULLIVAN, J.T. \& RICHARDS, C.S. Schistosoma mansoni, NIH-SM-PR-2 strain, in susceptible and non susceptible stocks of Biomphalaria glabrata: comparative histology. J. Parasit., 67: 702-8, 1981.

28. YOLLES, T.K.; MOORE, P.V.; DeGINSTI, D.L.; RIPSON, C.A.; MELENEY, H.E. A technique for the perfusion of laboratory animals for the recovery of schistosomes. $J$. Parasit., 33: 419-26, 1947.

Recebido para publicaçāo em 21/02/1991. Aprovado para publicaçāo em 05/07/1991. 